\title{
Production of Medium-Chain-Length Poly(3-Hydroxyalkanoates) from Saponified Palm Kernel Oil by Pseudomonas putida: Kinetics of Batch and Fed-Batch Fermentations
}

\author{
Annuar, M.S.M ${ }^{1^{*}}$, Tan, I.K.P ${ }^{2}$, Ibrahim, $\mathrm{S}^{3}$, and Ramachandran, K.B. ${ }^{4}$ \\ ${ }^{1,2}$ Institute of Biological Sciences, Faculty of Science, \\ ${ }^{3}$ Department of Civil Engineering, University of Malaya, 50603 Kuala Lumpur, Malaysia \\ ${ }^{4}$ Department of Biotechnology, Indian Institute of Technology (IIT) Madras, Chennai-600036, India \\ Email: suffian_annuar@um.edu.my
}

\begin{abstract}
The kinetics of medium-chain-length poly(3-hydroxyalkanoates), PHAMCL production by Pseudomonas putida PGA1 in batch and fed-batch fermentations were studied. With saponified palm kernel oil (SPKO) supplying the free fatty acids mixture as the sole carbon and energy source, $\mathrm{PHA}$ MCL accumulation is encouraged under ammonium-limited condition, which is a nitrogen stress environment. The amount of $\mathrm{PHA} \mathrm{A}_{\mathrm{MCL}}$ accumulated and its specific production rate, $\mathrm{q}_{\mathrm{PHA}}$ were influenced by the residual ammonium concentration level in the culture medium. It was observed that in both fermentation modes, when the residual ammonium was exhausted $\left(<0.05 \mathrm{gL}^{-1}\right)$, the $\mathrm{PHA} \mathrm{MCL}_{\mathrm{Mc}}$ accumulation $(11.9 \%)$ and $\mathrm{q}_{\mathrm{PHA}}\left(0.0062 \mathrm{~h}^{-1}\right)$ were significantly reduced. However, this effect can be reversed by feeding low amount of ammonium to the culture, resulting in significantly improved PHAMCL yield $(71.4 \%)$ and specific productivity $\left(0.6 \mathrm{~h}^{-1}\right)$. It is concluded that the feeding of low ammonium concentration to the culture medium during the PHAMCL accumulation has a positive effect on sustaining the $\mathrm{PHA}_{M C L}$ biosynthetic capability of the organism. It was also found that increasing SPKO concentration in the medium significantly reduced (up to $50 \%$ ) the volumetric oxygen transfer coefficient $\left(K_{L} a\right)$ of the fermentation system.
\end{abstract}

Keywords: poly-(3-hydroxyalkanoates), medium-chain-length, kinetics, ammonium, palm kernel oil.

\section{INTRODUCTION}

Poly(3-hydroxyalkanoates) (PHA) is a polymer of biological origin produced by a wide variety of microorganisms. The biopolymer has similar characteristics as the petrochemical derived plastics (Hocking and Marchessault, 1994). It has a huge potential of being an alternative to the synthetic plastics in numerous applications due to the fact that PHA is readily biodegradable. There are two major groups of PHAs: the short-chain-length PHA (PHA $\mathrm{SCL}_{\mathrm{S}}$ ) with five or less carbon atoms, and medium-chain-length $\mathrm{PHA}\left(\mathrm{PHA}_{\mathrm{MCL}}\right)$ with six or more carbon atoms. Only the $P H A_{S C L}$ have been commercially produced up to 500 tons per year, which was manufactured by Monsanto (Kellerhals et al., 2000). The $\mathrm{PHA}_{M C L}$ is yet to make a significant impact as a viable choice due to the fact that it is very expensive to produce this polymer in bulk amount even for material testing purposes. To date, the final $\mathrm{PHA}_{\mathrm{MCL}}$ yield and content obtained is relatively lower compared to those of $\mathrm{PHA} \mathrm{A}_{\mathrm{SCL}}$, which hampered development of its applications (Lee et al., 2000).

PHA $A_{M C L}$ copolymers can be produced using a variety of substrates including plant oils. Due to their long carbon number, these substrates have high energy content which is excellent for good cell growth and energy metabolism. Furthermore, the structural similarity of various fatty acids with the linear $P H A_{M C L}$ made it an even more attractive

${ }^{*}$ Corresponding author choice. Preliminary studies on the production of $\mathrm{PHA}$ MCL from renewable and cost-effective substrates like palm oil, palm kernel oil and their major fatty acids fractions by Pseudomonas putida have been reported (Tan et al., 1997).

PHA accumulation by bacteria is a response to the imbalance in growth environment, with excess carbon source and simultaneous limitation of nutrients such as nitrogen, phosphorus, oxygen, magnesium etc; this physiological condition can be exploited in the fermentation process to achieve high yields and productivity. Ammonium ion is usually chosen as the limiting nutrient as it is relatively easier to make a bacterial culture ammonium-limited than other mineral ions (Suzuki et al., 1986a).

Several $P H A_{M C L}$ production strategies in the bioreactor such as batch and continuous (Durner et al., 2001; Jung et al., 2001), fed-batch (Beom, 2002) and high-cell-density process (Lee et al., 2000) under various cultivation conditions have been described.

The aim of this study is to examine and compare the kinetics of $P H A_{M C L}$ production from heterogeneous fatty acids mixture (supplied as saponified palm kernel oil, SPKO) by Pseudomonas putida in an ammonium-limited batch and fed-batch fermentations. 


\section{MATERIALS AND METHODS}

\section{Microorganism}

Pseudomonas putida PGA1 strain was a gift from Professor G.Eggink from the Agrotechnological Research Institute, Wageningen, The Netherlands.

\section{Medium composition}

Medium for both inoculum cultivation and bioreactor studies was the mineral salt solution containing (in $\mathrm{gL}^{-1}$ ): 5.74, $\mathrm{K}_{2} \mathrm{HPO}_{4} ; 3.7, \mathrm{KH}_{2} \mathrm{PO}_{4} ; 1.0 \mathrm{ml}$ trace elements (MT) solution (Lageveen et al., 1988), $10.0 \mathrm{ml} 0.1 \mathrm{M}$ $\mathrm{MgSO}_{4} .7 \mathrm{H}_{2} \mathrm{O}$. Saponified palm kernel oil (SPKO) is supplied as the sole carbon and energy source with $\mathrm{NaNH}_{4} \mathrm{HPO}_{4} \cdot \mathrm{H}_{2} \mathrm{O}$ as the limiting nutrient. Saponification of palm kernel oil (PKO) was carried out according to Tan et al. (1997). PKO is the extract from the nut of the oil palm (Elaeis guineensis Jacq.) fruit. The oil consists of a mixture of C6-C18:2 fatty acids with approximately $82 \%$ saturated fatty acids and $18 \%$ unsaturated fractions (Table 1). The same medium composition was used for inoculum and fermenter cultivations to reduce or eliminate lag period.

To avoid precipitation during autoclaving, solutions of magnesium salt, trace elements and SPKO (pH 7.0) were sterilized separately before adding to the rest of the medium components.

Table 1: Fatty acids composition of palm kernel oil (Elson 1992)

\begin{tabular}{lc}
\hline \multicolumn{1}{c}{ Fatty acids } & Percentage (\%) \\
\hline C6:0 (caproic acid) & 0.2 \\
C8:0 (caprylic acid) & 3.0 \\
C10:0 (capric acid) & 4.0 \\
C12:0 (lauric acid) & 48.0 \\
C14:0 (myristic acid) & 16.0 \\
C16:0 (palmitic acid) & 8.0 \\
C18:0 (stearic acid) & 3.0 \\
C18:1 (oleic acid) & 15.4 \\
C18:2 (linoleic acid) & 2.4 \\
C20:0 (arachinoic acid) & 0.1 \\
& \\
SFA & \\
(SCFA) & \\
(MCFA) & 7.2 \\
(LCFA) $^{\text {b }}$ & 64.0 \\
MUFA $^{\mathrm{e}}$ & 11.1 \\
PUFA & 15.4 \\
\hline
\end{tabular}

${ }^{\text {a Saturated fatty acids }}$

${ }^{\mathrm{b}}$ Short chain SFA

${ }^{\circ}$ Medium chain SFA

${ }^{\mathrm{L}}$ Long chain SFA

${ }^{e}$ Monounsaturated fatty acids

${ }^{\text {f}}$ Polyunsaturated fatty acids

\section{Inoculum}

Inoculum in $120 \mathrm{ml}$ culture volume was grown in $500 \mathrm{ml}$ shake-flasks at $30^{\circ} \mathrm{C}$ and $250 \mathrm{rpm}$ rotation using Hotech Model 718 orbital shaker incubator (Hotech Instruments Corp., Taiwan). During active growth at $18 \mathrm{~h}$, the whole content of the flask was used to seed the bioreactor.

\section{Bioreactor}

Fermenter experiments were performed in a Biostat ${ }^{\circledR B} 3$ liter fermenter (B.Braun Biotech International). A round bottom culture vessel (Type B2) made of borosilicate glass and stainless steel equipped with an outer thermostat jacket was used. The main geometric characteristics of the fermenter are shown in Table 2. Temperature, $\mathrm{pH}$ and oxygen partial pressure $\left(\mathrm{pO}_{2}\right)$ were monitored and controlled by a computer system.

Table 2: Dimensions of the fermenter and its components

\begin{tabular}{lc}
\hline \multicolumn{1}{c}{ Design parameters } & Specifications \\
\hline Total volume & $3 \mathrm{~L}$ \\
Diameter of inner tank & $130 \mathrm{~mm}$ \\
Height of tank & $240 \mathrm{~mm}$ \\
Number of baffles & 4 \\
Baffle width & $10.5 \mathrm{~mm}$ \\
Type of impellers & Rushton disc turbine \\
Number of impellers & 2 \\
Distance between impellers & $79.5 \mathrm{~mm}$ \\
Distance of lower impeller from & $25 \mathrm{~mm}$ \\
bottom plate & \\
Impeller diameter of disc & $53 \mathrm{~mm}$ \\
Number of blades & 6 \\
Impeller blade width & $10.5 \mathrm{~mm}$ \\
Impeller blade length & $14.5 \mathrm{~mm}$ \\
Diameter of single ring sparger & $48 \mathrm{~mm}$ \\
Number of holes & 14 \\
Distance of ring sparger from & $20 \mathrm{~mm}$ \\
bottom plate & \\
\hline
\end{tabular}

\section{Estimation of volumetric oxygen transfer coefficient $\left(\mathrm{K}_{L} \mathrm{a}\right)$}

The estimation of volumetric oxygen transfer coefficient, $\mathrm{K}_{L} \mathrm{a}$ was carried out in a batch bioreactor using static gassing-out method. The aqueous phase consisted of actual composition of the fermentation medium in 1.0 liter distilled water. The liquid medium was deoxygenated by sparging gaseous nitrogen until all traces of oxygen were stripped away. Then air was sparged into the bioreactor at $0.5 \mathrm{vvm}$ and $600 \mathrm{rpm}$ agitation rate. The increase in the oxygen partial pressure $\left(\mathrm{pO}_{2}\right)$ was recorded at regular intervals until readings became constant which indicated the saturation of the liquid medium with oxygen. The $\mathrm{K}_{L} \mathrm{a}$ was determined using the relationship:

$\mathrm{dC}_{L} / \mathrm{d} t=\mathrm{K}_{L} \mathrm{a}\left(\mathrm{C}^{*}{ }_{L}-\mathrm{C}_{L}\right)$ 
where $C^{*}$ is the $\mathrm{pO}_{2}$ saturation value and $\mathrm{C}_{L}$ is the $\mathrm{pO}_{2}$ in the aqueous medium. Upon integration, equation (1) transformed into

$\ln \left(C^{*}-C_{L}\right)=-K_{L}$ a $\cdot t+\ln C^{*}{ }_{L}$

The plotting of In $\left(C^{*} L-C_{L}\right)$ versus $t$ yields a straight line with the $\mathrm{K}_{L} \mathrm{a}$ value determined directly from the slope.

\section{Batch fermentation}

Inoculum was added at $10 \%(\mathrm{v} / \mathrm{v})$ and the fermenter working volume after inoculation was $1.2 \mathrm{~L}$. The cells concentration at the start of fermenter cultivation was approximately $0.13 \mathrm{gL}^{-1}$. The temperature and the $\mathrm{pH}$ were maintained at $30( \pm 0.5){ }^{\circ} \mathrm{C}$ and $7.0( \pm 0.05)$, respectively; with the agitation rate of $600 \mathrm{rpm}$ and the aeration rate of $0.5 \mathrm{vvm}$ of filtered air. Silicone anti-foam (BDH) was included in the fermenter at $1.0 \mathrm{gL}^{-1}$. Samples were withdrawn at regular intervals.

\section{Fed-batch fermentation}

The fermentation was carried out using fermenter setup as in the batch with the addition of the feeding routine. The fermentation was performed as batch start-up and at $9 \mathrm{~h}$ the feeding commenced. Feeding medium $\left(0.4 \mathrm{gL}^{-1}\right.$ ammonium) consisted of fixed ratio of SPKO-toammonium (6.9mole:1mole) in the mineral salt solution. Feeding was carried out using Masterflex 7521-35 peristaltic pump at a constant flow rate of $0.14 \mathrm{~L} \mathrm{~h}^{-1}(0.056$ $\mathrm{g}$ ammonium $\mathrm{h}^{-1}$ ) to avoid total depletion of ammonium in the fermenter. The contents of the feed reservoir were continuously stirred using magnetic stirrer to obtain a homogenous feed into the fermenter. The approximate working volume for all fermentations should not exceed $1.5 \mathrm{~L}$ after taking into account the total volume of the feeding solution and $\mathrm{pH}$ adjustment.

\section{Analytical methods}

All measurements were performed in triplicates. Total biomass concentration was estimated by first spinning down the cells in pre-weighed micro-centrifuge tubes. The cells were then washed twice with saline solution and dried at $90^{\circ} \mathrm{C}$ till constant weight.

The residual ammonium in the cell-free culture medium was determined using spectrophotometric method (Solorzano, 1969). The residual free fatty acids from SPKO in the culture medium supernatant were estimated by solvent titration (Cocks and van Rede, 1966).

To obtain PHA production profile, $8.0 \mathrm{mg}$ of dried cells were subjected to acid-catalyzed methanolysis and the PHA amount and composition were determined by gas chromatography (GC) using benzoic acid methyl ester as the internal standard (Brandl et al., 1988). The gas chromatograph used was Varian Star $3400 \mathrm{CX}$ equipped with a fused silica capillary column $(30 \mathrm{~m} \times 0.53 \mathrm{~mm}$ ID) (Supelco SPB ${ }^{\mathrm{TM}}-608$ ) and a flame ionization detector.

\section{Data analysis and calculations}

The calculations for kinetics data were performed using MATLAB 6.1 software (The MathWorks Inc.).

Calculation for volumetric productivity of $\mathrm{PHA}_{\mathrm{MCL}}(\Phi)$ was according to Yamane (1992), as shown in equation (3).

$\Phi=[\mathrm{P}] /\left(\mathrm{t}_{d}+\mathrm{t}_{f}\right) \quad\left(\mathrm{g} \mathrm{L}^{-1} \mathrm{~h}^{-1}\right)$

where $[P]=P H A_{M C L}$ concentration $\left(\mathrm{gL}^{-1}\right) ; t_{d}=$ down time (h) and $t_{f}=$ fermentation time (h).

PHA $A_{M C L}$ yield from the SPKO supplied $\left(Y_{P / C}\right)$ for the batch fermentation was calculated as in equation (4):

$\mathrm{Y}_{\mathrm{P} / \mathrm{C}}=\Delta\left(\mathrm{PHA}_{\text {maximum }}-\mathrm{PHA}_{\text {initial }}\right) / \mathrm{SPKO}_{\text {supplied }}\left(\mathrm{g} \mathrm{PHA} \mathrm{g}{ }^{-1} \mathrm{SPKO}\right)$ (4)

where $\mathrm{PHA}_{\text {maximum }}=$ maximum mass of $\mathrm{PHA}(\mathrm{g})$ attained; $\mathrm{PHA}_{\text {initial }}=$ mass of $\mathrm{PHA}(\mathrm{g})$ at the start of cultivation; $\mathrm{SPKO}_{\text {supplied }}=$ mass of SPKO $(\mathrm{g})$ at the start of cultivation. Residual biomass yield from SPKO supplied $\left(Y_{R / C}\right)$ for batch fermentation was calculated as in equation (5):

$\mathrm{Y}_{\mathrm{R} / \mathrm{C}}=\Delta\left(\mathrm{R}_{\text {maximum }}-\mathrm{R}_{\text {initial }}\right) / \mathrm{SPKO}_{\text {supplied }}$ ( $\mathrm{g}$ residual biomass $\mathrm{g}^{-1}$ SPKO)

where residual biomass $=$ total biomass minus PHA mass (g); $R_{\text {maximum }}=$ maximum mass of residual biomass $(\mathrm{g})$ attained; $R_{\text {initial }}=$ mass of residual biomass $(g)$ at the start of cultivation.

In the case of fed-batch cultivation, the $\mathrm{PHA} \mathrm{A}_{\mathrm{MCL}}$ yield from the SPKO (YP/C) was calculated as in equation (6): $\mathrm{Y}_{\mathrm{P} / \mathrm{C}}=\Delta\left(\mathrm{PHA}_{\text {maximum }}-\mathrm{PHA}_{\text {initial }}\right) /\left(\mathrm{SPKO}_{\text {supplied }}+\mathrm{SPKO}_{\text {fed }}\right)$
$\left(\mathrm{g} \mathrm{PHA} \mathrm{g}^{-1} \mathrm{SPKO}\right)$

where $\mathrm{SPKO}_{\text {supplied }}+\mathrm{SPKO}_{\text {fed }}=$ mass of SPKO $(\mathrm{g})$ at the start of cultivation plus mass of SPKO added during feeding (g).

Residual biomass yield from SPKO supplied $\left(\mathrm{Y}_{\mathrm{R} / \mathrm{C}}\right)$ was calculated as in equation (7):

$\mathrm{Y}_{\mathrm{R} / \mathrm{C}}=\Delta\left(\mathrm{R}_{\text {maximum }}-\mathrm{R}_{\text {initial }}\right) /\left(\mathrm{SPKO}_{\text {supplied }}+\mathrm{SPKO}_{\text {fed }}\right)$ (g residual biomass $\mathrm{g}^{-1}$ SPKO)

\section{RESULTS}

\section{Effect of SPKO concentrations on the volumetric oxygen transfer coefficient $\left(K_{L} a\right)$}

Since SPKO is a highly reduced substrate metabolized through an aerobic $\beta$-oxidation pathway, adequate oxygen supply to the cells in the $P H A_{M C L}$ fermentation is important to maximize yield and productivity. Due to the soap-like properties of the SPKO, it would be reasonable to expect that its presence in the liquid medium might affect the efficiency of oxygen transfer to the fermentation system. Experiments to quantify this were carried out by determining the volumetric oxygen transfer coefficient, $\mathrm{K}_{L} \mathrm{a}$ $\left(\mathrm{s}^{-1}\right)$ in batch fermentation at increasing SPKO concentrations i.e. $\left(\mathrm{gL}^{-1}\right): 1.0,5.0,10.0,15.0$ and 20.0 . 
Similar conditions as in the actual fermentation were implemented during the procedure, with the following exceptions; (a) the determination was done under nonsterile conditions; (b) without the presence of the P.putida PGA1 biomass and; (c) SPKO concentrations in the bioreactor were increased by manual addition.

Only experimental results from SPKO concentrations of $1.0,5.0$ and $10.0 \mathrm{gL}^{-1}$ were obtained due to the problem of heavy foaming that occurred for the SPKO concentrations above $10.0 \mathrm{gL}^{-1}$. The foaming was extremely heavy during the $\mathrm{K}_{L} \mathrm{a}$ determination at SPKO concentration more than $10.0 \mathrm{~g} \mathrm{~L}^{-1}$ and hence the whole procedure had to be terminated. The estimated $\mathrm{K}_{L} \mathrm{a}$ values for the three SPKO concentrations tested are shown in Table 3.

Table 3: Estimated $\mathrm{K}_{L \mathrm{a}}$ values at different SPKO concentrations.

\begin{tabular}{cccc}
\hline & \multicolumn{3}{c}{ SPKO concentration $\left(\mathbf{g ~ L}^{-1}\right)$} \\
\cline { 2 - 4 } & $\mathbf{1 . 0}$ & $\mathbf{5 . 0}$ & $\mathbf{1 0 . 0}$ \\
\cline { 2 - 4 } $\mathrm{K}_{\mathrm{La}\left(\mathbf{s}^{-1}\right)}$ & $0.025( \pm 4 \%)$ & $0.028( \pm 4 \%)$ & $0.014( \pm 7 \%)$ \\
\hline
\end{tabular}

The $K_{L}$ a values for SPKO concentrations of 1.0 and $5.0 \mathrm{gL}^{-1}$ are very close to each other i.e. $0.025( \pm 4 \%) \mathrm{s}^{-1}$ and $0.028( \pm 4 \%) \mathrm{s}^{-1}$, respectively. However, an increase in SPKO concentration from 5.0 to $10.0 \mathrm{gL}^{-1}$ in the liquid medium caused a reduction in $\mathrm{K}_{L} \mathrm{a}$ value by $50 \%$. It is suggested that further increased in the SPKO concentration would have caused the $\mathrm{K}_{L}$ a to decline even further. This showed that the range of SPKO concentrations to be supplied batch wise should be between 5.0 to $10.0 \mathrm{gL}^{-1}$, and in fed-batch fermentation it should be controlled within this range by proper feeding of SPKO.

\section{Batch fermentation}

The initial amount of SPKO and ammonium provided were $5.0 \mathrm{gL}^{-1}$ and $0.4 \mathrm{gL}^{-1}$, respectively. SPKO was the sole carbon and energy source which was in excess for both growth and $\mathrm{PHA} \mathrm{MCL}_{\mathrm{M}}$ production, and ammonium was the limiting nutrient in the medium. Growth immediately commenced after inoculation (Figure 1A).

Cells proliferation continued until $12 \mathrm{~h}$ and a final 0.9 $\mathrm{gL}^{-1}$ concentration of total biomass was obtained. The increase in total biomass is due to both cellular growth and $\mathrm{PHA}_{M C L}$ accumulation inside the cells. The profile of ammonium utilization reflected the growth trend (Figure 1B).

The increase in $\mathrm{PHA}_{M C L}$ concentration followed closely the trend of growth, indicating that under the present conditions $\mathrm{PHA} \mathrm{MCL}_{\mathrm{C}}$ accumulation was growth associated (Figure 1C). In addition, the dynamics of intracellular $\mathrm{PHA}_{\mathrm{MCL}}$ content is shown in Figure 1D, which may not necessarily, follows closely the trend of concentration profiles of biomass and PHAMCL. Total biomass and $\mathrm{PHA} M \mathrm{MCL}$ concentration reached their maxima at $12 \mathrm{~h}$. Beyond $12 \mathrm{~h}$, a decrease of total biomass was observed until the end of fermentation. This was due to both the cells death and degradation of internal $\mathrm{PHA}$ via depolymerase action.

The time period where a decline in total biomass and active degradation of stored PHA coincided with the time period of ammonium exhaustion (from approximately 15$48 \mathrm{~h}$ ) where its concentration in the culture broth was lower than $0.05 \mathrm{gL}^{-1}$, which indicated severe exhaustion and remained so until the end. The concentration of free fatty acids in the medium within the cultivation period remained above $2.5 \mathrm{gL}^{-1}$, which was still in excess. No oxygen limitation was observed as its partial pressure was never less than $50 \%$ air saturation.

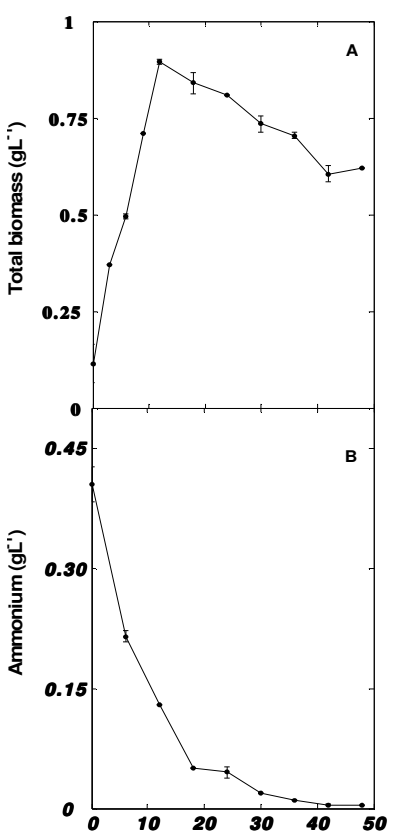

t (h)

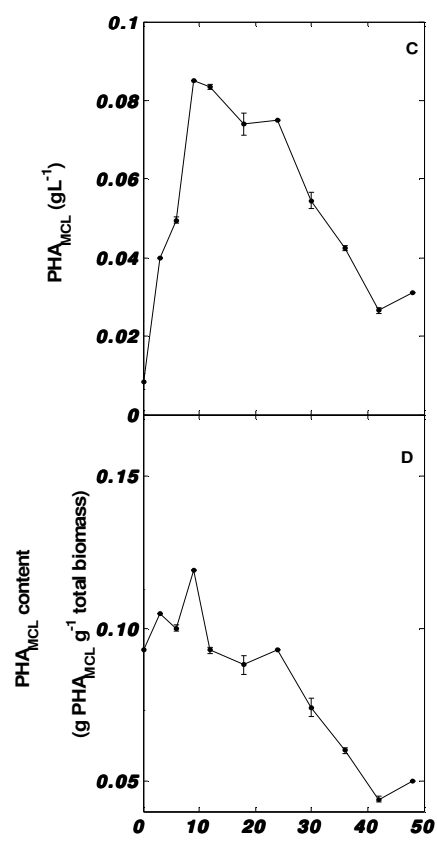

t (h)
Figure 1: Total biomass (A), ammonium (B), $\mathrm{PHA} \mathrm{A}_{\mathrm{MCL}}$ concentration $(C)$ and intracellular content (D) profiles during batch fermentation of P.putida PGA1.

Kinetics of $\mathrm{PHA} \mathrm{A}_{\mathrm{MCL}}$ biosynthesis in batch fermentation

In this batch culture, ammonium-limitation condition was characterized by active $P H A_{M C L}$ accumulation whereas ammonium-exhaustion condition was represented by active internal degradation of stored $\mathrm{PHA} \mathrm{A}_{\mathrm{MCL}}$.

The basis of specific PHA production rate, qPHA ( $g$ PHA produced $g^{-1}$ residual biomass $h^{-1}$ ) calculation was according to Suzuki et al. (1986b) and Yamane (1992) which is as follows: when the microorganism produces an intracellular storage material such as PHA, the total biomass $[\mathrm{X}]\left(\mathrm{gL}^{-1}\right)$ consists of two main parts, namely PHA $[\mathrm{P}]\left(\mathrm{gL}^{-1}\right)$ and residual biomass $[\mathrm{R}]\left(\mathrm{gL}^{-1}\right)$, where $[\mathrm{R}]$ is calculated as the difference between the total biomass and the mass of PHA i.e. $[R]=[X]-[P]$. Then the total biomass in the culture is given by equation (8):

$[\mathrm{X}] \cdot \mathrm{V}_{\text {broth }}=[\mathrm{P}] . \mathrm{V}_{\text {broth }}+[\mathrm{R}] \cdot \mathrm{V}_{\text {broth }}$ 
where $\mathrm{V}_{\text {broth }}$ is the working volume of the medium. $[R] . V_{\text {broth }}$ can be considered as the anabolically active biomass including proteins and nucleic acids. Therefore the GPHA based on the unit of residual biomass is described as follows:

$\mathrm{q}_{\mathrm{PHA}}=1 /\left([\mathrm{R}]_{t} \cdot \mathrm{V}_{\text {broth }}\right) \times d\left([\mathrm{P}] . \mathrm{V}_{\text {broth }}\right) / d t$

$=1 /\left(\left([\mathrm{X}]_{t}[\mathrm{P}]_{t}\right) \cdot \mathrm{V}_{\text {broth }}\right) \times d\left([\mathrm{P}] \cdot \mathrm{V}_{\text {broth }}\right) / d t$

The PHA accumulation data from batch fermenter (Figure $1 \mathrm{C})$ was fitted using $4^{\text {th }}$ degree polynomial (Figure $2 \mathrm{~A}$ ). The polynomial form was as follows:

$[\mathrm{P}](t)=-3.5\left(10^{-8}\right) t^{4}+8.5\left(10^{-6}\right) t^{3}-0.00056 t^{2}+0.012 t+$ 0.0081

where $[\mathrm{P}](t)$ represents $\mathrm{PHA} A_{M C L}$ concentration data as a function of time t.

The polynomial function was differentiated and subsequently evaluated with respect to the residual biomass concentration at a particular time $[R]_{t}$. This gave the $q_{P H A}\left(g\right.$ PHA $A_{M C L}$ produced $g^{-1} R h^{-1}$ ) in the batch fermenter.

It was clear that ammonium exhaustion in the liquid medium (Figure 2B) was not a conducive condition for effective $P H A_{M C L}$ production, because the $\mathrm{PHA} \mathrm{A}_{M C L}$ biosynthetic activities, as shown by the rapid decline of the organism's specific $P H A_{M C L}$ biosynthesis rate, QPHA $_{P H}$ (Figure 2C), were considerably reduced under this condition. The q $_{\mathrm{PHA}}$ calculated at the time when maximum $\mathrm{PHA}_{\mathrm{MCL}}$ has been accumulated intracellular $(11.9 \%$ from the total dry biomass) was approximately $0.0062 \mathrm{~g}$ PHA $A_{M C L}$ produced $g^{-1} R h^{-1}$. The volumetric productivity of $\mathrm{PHA}_{M C L}$ was calculated to be $0.0028 \mathrm{~g} \mathrm{~L}^{-1} \mathrm{~h}^{-1}$. Suzuki et al. $(1986 b)$ calculated the specific PHA $A_{S C L}$ formation rate, qPHA (g PHA $A_{S C L}$ formed $\mathrm{g}^{-1}$ residual biomass $\mathrm{h}^{-1}$ ) of Protomonas extorquens to be below 0.01 when the ammonium concentration in the liquid medium decreased to almost $0 \mathrm{ppm}$. Methanol was continuously supplied as a sole carbon and energy source in their cultivations.

Similar effect was observed by Bitar and Underhill (1990) in their batch culture of Alcaligenes eutrophus. They noted that without the ammonium supplementation at the beginning of $\mathrm{PHA} \mathrm{SCL}_{\mathrm{S}}$ accumulation phase, the PHA $A_{S C L}$ accumulation rate $\left(\mathrm{g} \mathrm{PHA} \mathrm{L}^{-1} \mathrm{~h}^{-1}\right)$ was below $0.1 \mathrm{~g}$ $\mathrm{L}^{-1} \mathrm{~h}^{-1}$. This is nearly $90 \%$ less than the maximum PHASCL accumulation rate attainable in their batch culture studies.

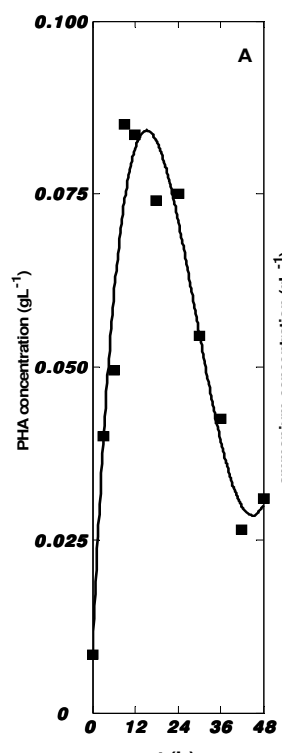

$\mathbf{t}(\mathrm{h})$

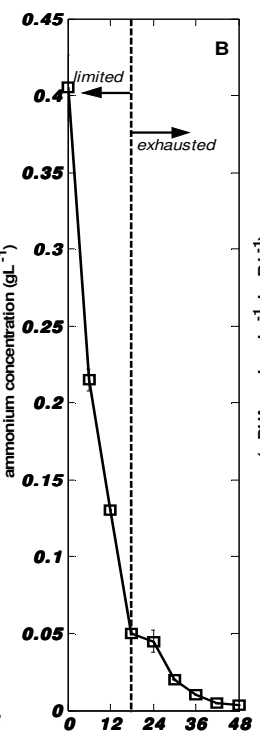

t (h)

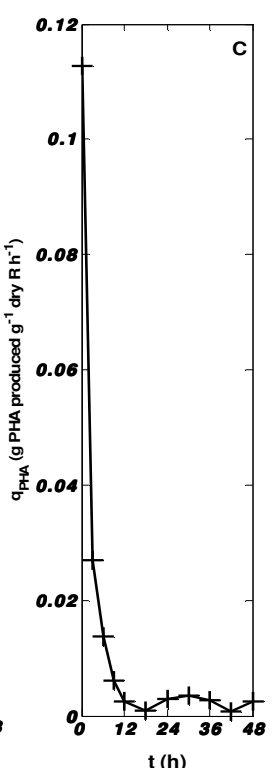

$t(h)$
Figure 2: Fitting of $P H A_{M C L}$ concentration time profile with $4^{\text {th }}$-degree polynomial. (A), the residual ammonium concentration with indicated limiting- and exhausted region (B), and the specific $P H A_{M C L}$ production rate (C) in batch fermentation.

\section{Fed-batch fermentation}

The cultivation was started in a batch mode $(1.0 \mathrm{~L})$ and fed-batch was initaited via feeding. The initial amount of SPKO and ammonium in the fermenter were $5.0 \mathrm{gL}^{-1}$ and $0.16 \mathrm{gL}^{-1}$, respectively.

In the batch start-up phase, the cellular growth and intracellular $\mathrm{PHA} \mathrm{MCL}_{\mathrm{C}}$ accumulation contributed to the increase in the concentration of total biomass (Figure $3 \mathrm{~A}$ ). Final total biomass obtained was $2.1( \pm 0.1) \mathrm{gL}^{-1}$. The consumption of ammonium followed the growth trend until the commencement of feeding (Figure 3B).

The mass of $R$ remained essentially constant from the start of feeding $(\sim 0.83 \pm 0.04 \mathrm{~g})$ until the end of the experiment $(\sim 0.84 \pm 0.02 \mathrm{~g})$. This shows that the increase in the total biomass was largely due to the increase in the $\mathrm{PHA}_{\mathrm{MCL}}$ amount being accumulated intracellular by the cells. Between 0-4 h, an increase in PHA $A_{M C L}$ concentrations were observed (Figure $3 \mathrm{C}$ ). However, a slight decline occurred after $4 \mathrm{~h}$ until the beginning of feeding, where the $\mathrm{PHA} M \mathrm{MCL}$ concentrations started to increase again. The $P H A_{M C L}$ content of the cells also decreased from approximately $0.5 \mathrm{~g}^{\mathrm{PHA}} \mathrm{A}_{\mathrm{MCL}} \mathrm{g}^{-1}$ total biomass at $t=0 \mathrm{~h}$ to $0.3 \mathrm{~g} \mathrm{PHA}_{M C L} \mathrm{~g}^{-1}$ total biomass at $\mathrm{t}=8 \mathrm{~h}$, prior to the start of feeding (Figure 3D). When the feeding commenced, $\mathrm{PHA} \mathrm{MCL}_{\mathrm{M}}$ content of the cells increased dramatically up to $0.7 \mathrm{~g} \mathrm{PHA}_{\mathrm{MCL}} \mathrm{g}^{-1}$ total biomass and remained so until the end of the fermentation. The ammonium concentration in the culture medium during the feeding period increased temporarily, and approaching $0.02 \mathrm{gL}^{-1}$ at $10 \mathrm{~h}$. After that, it decreased to near zero at 
the end of fermentation. The decline of $\mathrm{PHA} M \mathrm{MCL}$ concentration and its content coincided with the exhaustion of ammonium; with the concentration in the culture broth $<0.05 \mathrm{gL}^{-1}$ (Figure 3B). Similarly, this was observed in the batch fermentation i.e. when ammonium concentration $<0.05 \mathrm{gL}^{-1}$ in culture broth. This is regardless of the initial ammonium concentrations used in this study, which was $0.4 \mathrm{gL}^{-1}$ and $0.16 \mathrm{gL}^{-1}$ for the batch and fed-batch fermentations, respectively. The decline of $\mathrm{PHA}_{\mathrm{MCL}}$ concentrations and content is ascribed to the action of intracellular $\mathrm{PHA}$ MCL depolymerase.

The free fatty acids concentrations were estimated to be no less than $4.0 \mathrm{gL}^{-1}$ throughout the fermentation, and the oxygen partial pressure was never less than $50 \%$. $t(h)$

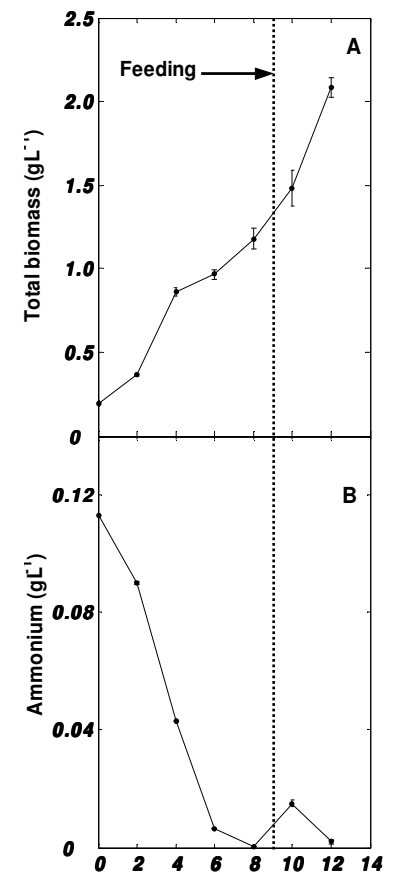

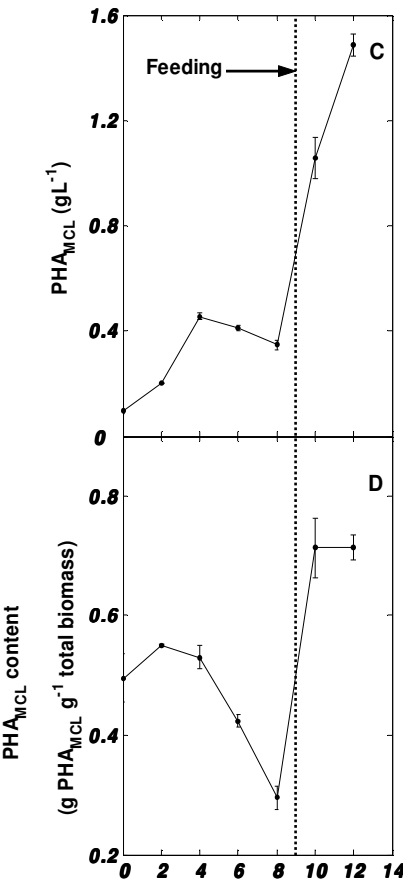

t (h)
Figure 3: Total biomass (A), ammonium (B), $\mathrm{PHA} M \mathrm{MLL}$ concentration $(C)$ and intracellular content (D) profiles during fed-batch fermentation of P.putida PGA1.

\section{Kinetics of $\mathrm{PHA}_{\mathrm{MCL}}$ biosynthesis in fed-batch fermentation}

The nitrogen source feeding (0.056 $\mathrm{g}$ ammonium $\mathrm{h}^{-1}$ ) together with SPKO was to supply low concentration of ammonium and excess carbon source in the form of free fatty acids during the $P H A_{M C L}$ biosynthesis stage.

The calculation for the Q $_{\mathrm{PHA}}$ was the same as described for the batch cultivation with the exception that the culture volume $\left(\mathrm{V}_{\text {broth }}\right)$ is increasing with time. The $\mathrm{PHA} \mathrm{ACL}_{\mathrm{MC}}$ accumulation data from fed-batch fermenter was fitted using $4^{\text {th }}$ degree polynomial (Figure $4 \mathrm{~A}$ ). The polynomial form was as follows:

$[\mathrm{P}](t)=-0.00018 t^{4}+0.0067 t^{3}+0.062 t^{2}+0.22 t+0.068(11)$
From Figure $4 \mathrm{~B}$, it can be seen that during the batch start-up phase of the cultivation, ammonium concentrations in the culture medium gradually declined to become almost zero. This resulted in a rapid reduction in the specific $\mathrm{PHA}_{\mathrm{MCL}}$ biosynthesis rate, $\mathrm{q}_{\mathrm{PHA}}$ (Figure $4 \mathrm{C}$ ). However, when the feeding begins, certain level of ammonium remained was present in the culture liquid rather than completely exhausted, and the $\mathrm{q}_{\mathrm{PHA}}$ started to recover and reached the maximum rate of approximately $0.6 \mathrm{~g} \mathrm{PHA}_{\mathrm{MCL}}$ produced $\mathrm{g}^{-1} \mathrm{R} \mathrm{h}^{-1}$; with only a slight decrease until the termination of the experiment at $12 \mathrm{~h}$. The volumetric productivity of $\mathrm{PHA} \mathrm{A}_{\mathrm{MCL}}$ for the fed-batch fermentation is $0.07 \mathrm{~g} \mathrm{~L}^{-1} \mathrm{~h}^{-1}$. Jung et al. (2001) obtained

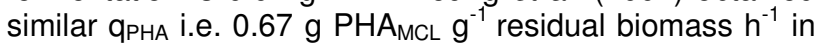
the chemostat cultivation of $P$.oleovorans using $n$-octane as carbon source.

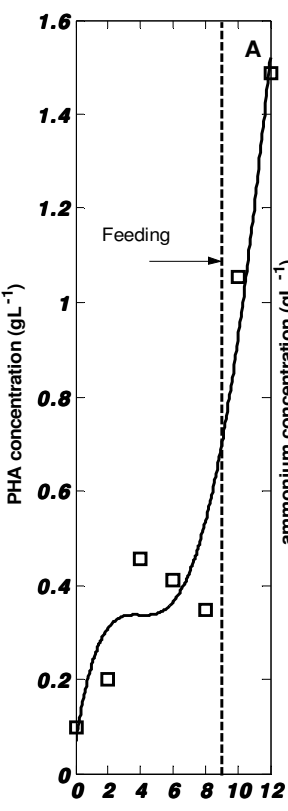

$\mathrm{t}$ (h)

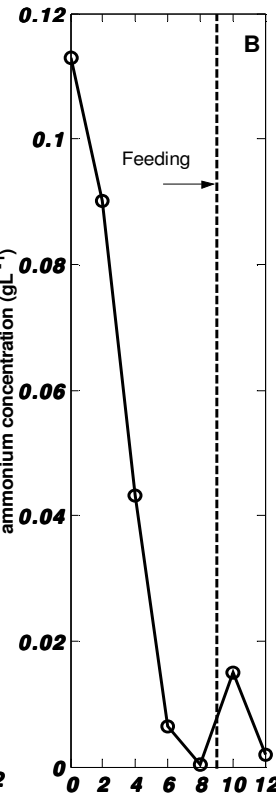

$\mathrm{t}(\mathrm{h})$

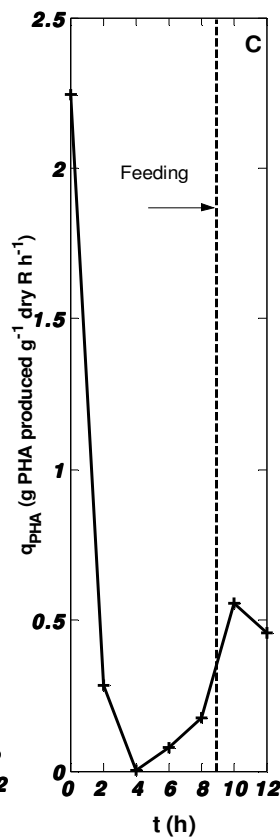

$\mathrm{t}(\mathrm{h})$
Figure 4: Fitting of $P H A_{M C L}$ concentration time profile with $4^{\text {th }}$-degree polynomial $(A)$, the residual ammonium concentration profile $(\mathrm{B})$, and the specific $P H A_{M C L}$ production rate $(C)$ in fed-batch fermentation.

In fed-batch cultures using fixed-rate ammonia feeding, $60 \%$ PHA extorquens was obtained faster at 58hours with constant ammonia feeding rate at $0.08 \mathrm{~g} \mathrm{~h}^{-1}$, as compared to nearly $100 \mathrm{~h}$ for the same PHA $\mathrm{SCL}_{\mathrm{S}}$ content in the case without ammonia feeding (Suzuki et al., 1986b). Improved volumetric $\mathrm{PHA} S \mathrm{SC}$ synthesis rate from 0.1 to $0.99 \mathrm{~g}$ PHA $A_{S C L}$ produced $\mathrm{L}^{-1} \mathrm{~h}^{-1}$ was recorded by Bitar and Underhill (1990) during the period of ammonium supplementation to the batch culture of Alcaligenes eutrophus. A similar effect was seen with regards to the maximal specific rate of monomer production of $\mathrm{PHASCL}$ 
(0.125 g 3-hydroxyalkanoates monomer produced $\mathrm{g}^{-1}$ residual biomass $\mathrm{h}^{-1}$ ), where the rate was maintained for longer periods in nitrogen fed cultures than in the nitrogen exhausted culture (Aragao et al., 1996).

The results obtained here are also comparable to that of $\mathrm{pH}$-stat fed-batch fermentation using carbon-to-nitrogen (C:N) ratio of $20 \mathrm{~g}$ octanoic acid $\mathrm{g}^{-1}$ ammonium nitrate (Beom, 2002). Using P.oleovorans, the highest PHA $\mathrm{MCL}_{\mathrm{MC}}$ content of $75 \%$ was obtained at this C: $\mathrm{N}$ ratio with $0.63 \mathrm{~g}$ $\mathrm{L}^{-1} \mathrm{~h}^{-1}$ productivity.

In this study, the deterioration in the specific $\mathrm{PHA} M \mathrm{MCL}$ production rate by P.putida PGA1 was successfully reversed by feeding mineral salt solution which contains fixed ratio of SPKO-to-ammonium. Furthermore, the feeding enhances the biosynthesis of PHA as seen by the concomitant increase in both the $\mathrm{PHA} \mathrm{A}_{\mathrm{MCL}}$ concentration and content. The feeding of low ammonium concentration in the medium has a positive effect on the culture viability and in boosting the PHA accumulation.

\section{Comparison between batch and fed-batch cultivations}

The performance between the two cultivation modes was evaluated in terms of their volumetric and specific productivities, yield, biomass concentration, product concentration and PHA content (Table 4). It is clear that the fed-batch cultivation mode is superior to batch cultivation in every respect. In terms of volumetric productivity, $\Phi$, the fed-batch is at least 25 times higher than the batch.

Table 4: Comparison between the batch and fed-batch fermentation modes.

\begin{tabular}{|c|c|c|c|c|c|c|}
\hline $\begin{array}{l}\text { Cultivation } \\
\text { mode }\end{array}$ & $\underset{\left(g^{-1}\right)}{X}$ & $\underset{\left(g^{-1}\right)}{P}$ & $\begin{array}{l}\mathbf{P} / \mathbf{X} \\
(\%)\end{array}$ & $\begin{array}{c}\Phi \\
\left(g^{-1} h^{-1}\right)\end{array}$ & $\begin{array}{c}Y_{P / C} \\
\left(g^{-1}\right)\end{array}$ & $\begin{array}{c}\mathrm{qPHA}_{\mathrm{P} \mathrm{a}^{-1}} \\
\left(\mathrm{gP} \mathrm{P}^{-1} \mathrm{R}\right. \\
\left.\mathrm{h}^{-1}\right)\end{array}$ \\
\hline Batch & $\begin{array}{r}0.90 \\
\pm 0.01 \\
\end{array}$ & $\begin{array}{l}0.09 \\
\pm 0.0 \\
\end{array}$ & $\begin{array}{l}11.9 \\
\pm 0.0 \\
\end{array}$ & 0.0028 & 0.02 & 0.0062 \\
\hline Fed-batch & $\begin{array}{c}2.1 \\
\pm 0.1\end{array}$ & $\begin{array}{c}1.49 \\
\pm 0.04\end{array}$ & $\begin{array}{r}71.4 \\
\pm 2.0\end{array}$ & 0.07 & 0.11 & 0.6 \\
\hline
\end{tabular}

Keys: Maximum total biomass concentration, $\mathbf{X}$; maximum $\mathrm{PHA}$ concentration, $\mathbf{P}$; maximum $\mathrm{PHA}$ content, $\mathbf{P} / \mathbf{X} ; \mathrm{PHA}_{\mathrm{MCL}}$ volumetric productivity, $\boldsymbol{\Phi} ; \mathrm{PHA}_{\mathrm{MCL}}$ yield from SPKO supplied, $\mathbf{Y}_{\mathrm{P} / \mathrm{C}} ;$ specific $\mathrm{PHA}_{\mathrm{MCL}}$ production rate, $\mathbf{q}_{\mathrm{PHA}}$.

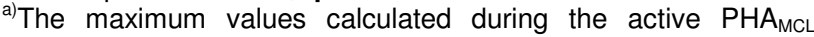
accumulation phase under ammonium-limitation.

Bitar and Underhill (1990) reported higher PHA content ca. $70 \%$ was achieved by ammonium supplementation to the batch culture of Alcaligenes eutrophus as compared to $59 \%$ without ammonium supply. In addition, PHA $A_{S C L}$ yield from glucose was $0.2 \mathrm{~g}$ PHA $S C L g^{-1}$ glucose in normal batch culture compared with $0.447 \mathrm{~g} \mathrm{PHB} \mathrm{g}^{-1}$ glucose in the ammonium supplemented culture.

It is clear that feeding with a small quantity of ammonium during the PHA accumulation phase improved the qPHA $_{\text {of }}$ the Putida PGA1 under ammonium-limited condition, resulting in higher $\mathrm{PHA}$ concentration and content. This was opposite of the cultivation without

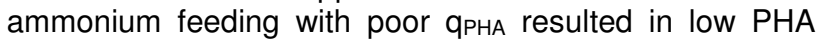
concentration and content.

\section{DISCUSSION AND CONCLUSION}

The presence of small amount of ammonium in the fermentation culture is important to maintain the growth capacity of the organism, as only viable residual biomass has the biochemical capability to synthesize and store the PHA. Thus, even though nitrogen source limitation stimulated PHA synthesis, complete nitrogen deficiency is detrimental to microbial $\mathrm{PHA} M \mathrm{MCL}$ biosynthetic activity as was observed in the batch fermentation. Exhaustion of ammonium is detrimental to culture physiology resulting in biomass death and biodegradation of stored PHA $\mathrm{ACL}_{\mathrm{MC}}$. It is hypothesized that certain amount of residual nitrogen is needed by the metabolizing cells during active $\mathrm{PHA} M$ production phase. The cultivation condition should be maintained under "ammonium limited" rather than "ammonium exhausted" in order to sustain culture viability and $\mathrm{PHA}_{\mathrm{MCL}}$ biosynthesis capability. Other published works showed that biomass and PHA concentrations continue to increase, or at least remained stable after ammonium concentration dropped to extremely low values in batch fermentation (Sonnleitner et al., 1979; Heinzle and Lafferty, 1980; Mulchandani et al., 1989; Belfares et al., 1995; Durner et al., 2001). Bacterial strains used in these studies were Alcaligenes eutrophus and Pseudomonas oleovorans. Similar results however, were not observed in our experiments.

Kim et al. (1997) suggested that there would exist some optimal concentrations of ammonium and dissolved oxygen to maintain cell viability high enough to accumulate $\mathrm{PHA} \mathrm{A}_{\mathrm{MCL}}$ since its concentration depends on both the cell concentration and its cellular content; therefore, a minimal supply of these are necessary to achieve a high PHA productivity in a jar fermenter operation. This was based on their results from the twostep fed-batch fermentation of P.putida BM01 using combined glucose and octanoate as carbon sources. Ammonium was used as the limiting nutrient and supplied in a fixed ratio to octanoate in feeding solution during the $\mathrm{PHA} \mathrm{A}_{\mathrm{MCL}}$ accumulation phase.

Hence, it is concluded that PHAMCL production can be improved by feeding low concentration of ammonium to the culture medium. This is supported by the comparison of the PHA $\mathrm{ACL}_{\text {p }}$ production kinetics from the batch and fedbatch fermentations in this study.

\section{NOMENCLATURE}

\section{Abbreviations}

$\mathrm{PHA}_{\mathrm{MCL}} \quad$ medium-chain-length poly-(3-hydroxyalkanoates)

$\mathrm{PHA}$ sCL short-chain-length poly(3-hydroxyalkanoates)

PKO palm kernel oil

SPKO saponified palm kernel oil 


\begin{tabular}{|c|c|}
\hline Symbols & \\
\hline$\Phi$ & volumetric productivity of $\mathrm{PHA} \mathrm{A}_{\mathrm{MCL}}, \mathrm{g} \mathrm{L}^{-1} \mathrm{~h}^{-1}$ \\
\hline $\begin{array}{l}\mathrm{PHA}_{\text {initial }} \\
\mathrm{PHA}_{\text {maximum }}\end{array}$ & $\begin{array}{l}\text { mass of PHA at the start of cultivation, } g \\
\text { maximum mass of PHA, } g\end{array}$ \\
\hline $\mathrm{q}_{\mathrm{PHA}}$ & $\begin{array}{l}\text { specific PHA production rate, g PHA } \mathrm{g}^{-1} \\
\text { residual biomass } \mathrm{h}^{-1}\end{array}$ \\
\hline $\mathrm{R}$ & residual biomass \\
\hline $\mathrm{R}_{\text {initial }}$ & $\begin{array}{l}\text { mass of residual biomass at the start of } \\
\text { cultivation, } g\end{array}$ \\
\hline $\mathrm{R}_{\text {maximum }}$ & $\begin{array}{l}\text { maximum mass of residual biomass } \\
\text { attained, } g\end{array}$ \\
\hline $\mathrm{SPKO}_{\text {supplied }}$ & $\begin{array}{l}\text { mass of SPKO supplied at the start of } \\
\text { cultivation, } g\end{array}$ \\
\hline $\begin{array}{l}\mathrm{SPKO}_{\text {fed }} \\
\mathrm{t}_{d}\end{array}$ & $\begin{array}{l}\text { mass of SPKO added during feeding, } g \\
\text { fermenter downtime, } \mathrm{h}\end{array}$ \\
\hline$t_{f}$ & fermentation time, $\mathrm{h}$ \\
\hline$V_{\text {broth }}$ & working volume of the fermenter, $\mathrm{L}$ \\
\hline$Y_{P / C}$ & PHA yield from SPKO, g PHA $\mathrm{g}^{-1}$ SPKO \\
\hline $\mathrm{Y}_{\mathrm{R} / \mathrm{C}}$ & $\begin{array}{l}\text { residual biomass yield from SPKO, } \mathrm{g} \mathrm{R} \mathrm{g}^{-1} \\
\text { SPKO }\end{array}$ \\
\hline [P] & PHA concentration, $\mathrm{gL}^{-1}$ \\
\hline$[R]$ & residual biomass concentration, $\mathrm{gL}^{-1}$ \\
\hline [X] & total biomass concentration, $\mathrm{gL}^{-1}$ \\
\hline
\end{tabular}

Subscript

$t \quad$ time, hour

\section{ACKNOWLEDGEMENTS}

This research was funded by the University of Malaya (grant no. Vot F0156/2001A).

\section{REFERENCES}

Aragao, G.M.F., Lindley, N.D., Uribelarrea, J.L. and Pareilleux, A. (1996). Maintaining a controlled residual growth capacity increases the production of polyhydroxyalkanoate copolymers by Alcaligenes eutrophus. Biotechnology Letters 18: 937-942.

Belfares, L., Perrier, M., Ramsay, B.A., Ramsay, J.A., Jolicoeur, M. and Chavarie, C. (1995). Multiinhibition kinetic model for the growth of Alcaligenes eutrophus. Canadian Journal of Microbiology 41: 249256.

Beom, S.K. (2002). Production of medium chain length polyhydroxyalkanoates by fed-batch culture of Pseudomonas oleovorans. Biotechnology Letters 24: 125-130.

Bitar, A. and Underhill, S. (1990). Effect of ammonium supplementation on production of poly- $\beta$ hydroxybutyric acid by Alcaligenes eutrophus in batch culture. Biotechnology Letters 12: 563-568.

Brandl, H, Gross, R.A, Lenz, R.W, Fuller, R.C. (1988). Pseudomonas oleovorans as a source of poly $(\beta$ hydroxyalkanoates) for potential applications as biodegradable polyesters. Applied and Environmental Microbiology 54: 1977-1982.

Cocks, L.V. and van Rede, C. (1966). Laboratory handbook for oil and fat analysts. Academic Press. London. p. 113-117.
Durner, R., Zinn, M., Witholt, B. and Egli, T. (2001). Accumulation of poly[(R)-3-hydroxyalkanoates] in Pseudomonas oleovorans during growth in batch and chemostat culture with different carbon sources. Biotechnology and Bioengineering 72: 278-288.

Elson, C.E. (1992). Tropical oils: nutritional and scientific issues. Critical Reviews in Food Science and Nutrition 31 (1/2): 79-102.

Heinzle, E. and Lafferty, R.M. (1980). A kinetic model for growth and synthesis of poly- $\beta$-hydroxybutyric acid (PHB) in Alcaligenes eutrophus H16. European Journal of Applied Microbiology and Biotechnology 11: 8-16.

Hocking, P.J. and Marchessault, R.H. (1994) Biopolyesters. In: Chemistry and Technology of Biodegradable Polymers. Griffin, G.S.L. (Ed.). Blackie Academic and Professional, Chapman and Hall, p. 48-96.

Jung, K., Hazenberg, W., Prieto, M. and Witholt, B. (2001). Two-stage continuous process development for the production of medium-chain-length poly(3hydroxyalkanoates). Biotechnology and Bioengineering 72: 19-24.

Kellerhals, M.B., Kessler, B., Witholt, B., Tchouboukov, A. and Brandl, H. (2000). Renewable long-chain fatty acids for the production of biodegradable medium-chain-length polyhydroxyalkanoates (mcl-PHAs) at laboratory and pilot plant scales. Macromolecules 3: 4690-4698.

Kim, G.J, Lee, I.Y, Yoon, S.C, Shin, Y.C, Prak, Y.H. (1997). Enhanced yield and high production of medium-chain-length poly(3-hydroxyalkanoates) in a two-step fed-batch cultivation of Pseudomonas putida by combined use of glucose and octanoate. Enzyme and Microbial Technology 20: 500-505.

Lageveen, R.G, Huisman, G.W, Preusting, H, Ketelaar, P, Eggink, G, Witholt, B. (1988). Formation of polyesters by Pseudomonas oleovorans: effect of substrates on formation and composition of poly-(R)3-hydroxyalkanoates and poly-(R)-3-hydroxyalkenoates. Applied and Environmental Microbiology 54: 2924-2932.

Lee, S.Y., Wong, H.H., Choi, J.I., Lee, S.H., Lee, S.C. and Han, C.S. (2000). Production of medium-chainlength polyhydroxyalkanoates by high-cell-density cultivation of Pseudomonas putida under phosphorus limitation. Biotechnology and Bioengineering 68: 466470.

Mulchandani, A., Luong, J.H.T. and Groom, C. (1989). Substrate inhibition kinetics for microbial growth and synthesis of poly- $\beta$-hydroxybutyric acid by Alcaligenes eutrophus ATCC 17697. Applied Microbiology and Biotechnology 30: 11-17.

Solorzano, L. (1969). Determination of ammonia in natural waters by the phenolhypochlorite method. Limnology and Oceanography 14: 799-801.

Sonnleitner, B., Heinzle, E., Braunegg, G. and Lafferty, R.M. (1979). Formal kinetics of poly- $\beta$-hydroxybutyric acid (PHB) production in Alcaligenes eutrophus H16 and Mycoplana rubra $R 14$ with respect to the 
dissolved oxygen tension in ammonium-limited batch culture. European Journal of Applied Microbiology and Biotechnology 7: 1-10.

Suzuki, T., Yamane, T. and Shimizu, S. (1986a) Mass production of poly- $\beta$-hydroxybutyric acid by fully automatic fed-batch culture of methylotroph. Applied Microbiology and Biotechnology 23: 322-329.

Suzuki, T., Yamane, T. and Shimizu, S. (1986b). Kinetics and effect of nitrogen source feeding on production of poly- $\beta$-hydroxybutyric acid by fed-batch culture. Applied Microbiology and Biotechnology 24: 366-369.
Tan, I.K.P, K.Sudesh Kumar, Theanmalar, M, Gan, S.N, B.Gordon III (1997). Saponified palm kernel oil and its major free fatty acids as carbon substrates for the production of polyhydroxyalkanoates in Pseudomonas putida PGA1. Applied Microbiology and Biotechnology 47: 207-211.

Yamane, T. (1992). Cultivation engineering of microbial bioplastics production. FEMS Microbiological Review 103: 257-264. 